\title{
Comparative Study of Pure and Doped Single Crystals of Lead Iodide Dihydrate and Lead Tartrate Dihydrate Grown in Silica Gel Using Fourier Transform Raman Spectra
}

\author{
G. Lillybai ${ }^{1}$ and M. H. Rahimkutty ${ }^{2}$ \\ ${ }^{1}$ Department of Physics, Department of Chemistry, Mahatma Gandhi College, Thiruvananthapuram-695004, India \\ ${ }^{2}$ M.S.M College Kayamkulum, kayamkulam 690 502, India \\ Correspondence should be addressed to G. Lillybai, glillybai@rediffmail.com
}

Received 21 January 2010; Revised 19 April 2010; Accepted 6 July 2010

Academic Editor: Ali Hussain Reshak

Copyright (C) 2010 G. Lillybai and M. H. Rahimkutty. This is an open access article distributed under the Creative Commons Attribution License, which permits unrestricted use, distribution, and reproduction in any medium, provided the original work is properly cited.

It is presented the FT-Raman spectroscopic investigation of the lead tartrate dihydrate and lead iodide dihydrate.The difference in the spectroscopic behavior of these salts were found which can be attributed to a different geometry of the tartrate and iodide ions. The structural differences between the coordination environments of lead atoms are discussed in connection with Raman frequencies. The compounds have been synthesized using sodium metasilicate gel at ordinary temperature and pressure.

\section{Introduction}

Lead iodide $\left(\mathrm{PbI}_{2}\right)$ is a very important material with a technological applicability as a room temperature detector. It is a wide-band-gap semiconductor $(\mathrm{Eg}>2 \mathrm{eV})$ with high environmental stability efficiency [1-5]. Recently, its bandgap energy and thermal properties were determined by photo acoustic spectroscopy $[5,6]$. The electronic and optical properties of lead iodide have been investigated experimentally by means of optical absorption and spectroscopic ellisometry, and theoretically by a full-potential linear muffin-tin-orbital method $[7,8], \mathrm{PbI}_{2}$ has been recognized as a very promising detector material with large technological applicability [9]. The single crystals of lead iodide have been grown by gel method. The observations of the faces of these crystals revealed that they have grown layer-by-layer as well as spiral mechanisms $[7,8,10,11]$. In order to study the electronic structure of $\mathrm{PbI}_{2}$ [11-15], the spin-orbit coupling was included. The dielectric function was calculated in the momentum representation [16-18]. From the literature survey shows that there is a very small anisotropy in the optical properties of $\mathrm{PbI}_{2}$ [17-22]. The triangular growth spirals, which are not clearly resolved. But these triangular spirals are seen to be oriented at the site of triangular etch pits produce during the growth processes [23-25]. In fact there is an interlocking of spirals which are oriented anticlockwise and clockwise direction. Lead tartrate initially grew as dendrites because of the large latent heat of crystallization and poor ionic conductivity [26]. The phenomenon of transformation of dendrites into single crystals indicates that it may be useful in the growth of single crystals of materials which normally grow as dendrites. It is now well-established that surface energy and surface diffusion are decisive factors on the shape stability of spherical particles. But the reduction in size is remarkable in the case of cadmium doped crystals.

\section{Experimental}

2.1. Synthesis of Lead Iodide Single Crystals. Dissolve $244 \mathrm{~g}$ of sodium metasilicate in $500 \mathrm{~mL}$ of double distilled water to obtain the stock solution $7.5 \mathrm{~mL}$ of stock solution is diluted with equal quantity of water. Then $15 \mathrm{~mL}$ of $2 \mathrm{M}$ acetic acid and $6 \mathrm{ml}$ of $1 \mathrm{M}$ lead acetate are combined, with continued agitation. The mixture is allowed to set, and $20 \mathrm{~mL}$ of $0.75 \mathrm{M}$ potassium iodide are then placed on the top of gel without ant disturbances Good hexagonal plates of lead iodide grow within about three weeks with deep yellowish and luminescent in nature. Zinc acetate is used as dopant 
TABle 1: Comparative study on the spectral datas of $\mathrm{PbI}_{2} \cdot 2 \mathrm{H}_{2} \mathrm{O} \& \mathrm{PbC}_{4} \mathrm{H}_{4} \mathrm{O}_{6} \cdot 2 \mathrm{H}_{2} \mathrm{O}$.

\begin{tabular}{|c|c|c|c|c|c|}
\hline $\begin{array}{l}\text { Pure } \mathrm{PbI}_{2} \\
\text { Bands } \\
\mathrm{cm}^{-1}\end{array}$ & $\begin{array}{l}\text { Doped } \\
\mathrm{PbI}_{2} \text { bands } \\
\mathrm{cm}^{-1}\end{array}$ & Assignment of bands & $\begin{array}{l}\text { Pure } \\
\mathrm{PbC}_{4} \mathrm{H}_{4} \mathrm{O}_{6} \\
\text { bands } \\
\mathrm{cm}^{-1}\end{array}$ & $\begin{array}{l}\text { Doped } \\
\mathrm{PbC}_{4} \mathrm{H}_{4} \mathrm{O}_{6} \\
\text { bands } \\
\mathrm{cm}^{-1}\end{array}$ & Assignment of bands \\
\hline 3012 & 3254 & OH stretching & 2965 & $\begin{array}{l}2940 \\
2918\end{array}$ & $\begin{array}{l}\text { asymmetric and symmetric } \\
\text { stretch of } \mathrm{C}-\mathrm{H}\end{array}$ \\
\hline 2515 & 2516 & $\mathrm{O}-\mathrm{H}$ tortional & 1598 & 1574 & \multirow{3}{*}{$\begin{array}{l}\mathrm{H}-\mathrm{O}-\mathrm{H} \text { bending, } \\
\mathrm{O}-\mathrm{H} \text { tortional mode }\end{array}$} \\
\hline 2336 & 2335 & mode and & 1419 & 1440 & \\
\hline 2312 & 2310 & interaction with & 1299 & 1392 & \\
\hline 2267 & 2267 & $\begin{array}{l}\text { other molecule with } \\
\text { interaction between the } \\
\text { hydroxyl group }\end{array}$ & 1236 & 1308 & \multirow{3}{*}{$\begin{array}{l}\text { Fermi Resonance } \\
\text { producing splitting of } \\
\text { carbonyl group }\end{array}$} \\
\hline 2243 & 2221 & \multirow{2}{*}{$\begin{array}{l}\text { The splitting provides } \\
\text { direct insight into the }\end{array}$} & 1124 & 1276 & \\
\hline 2122 & 2184 & & 1066 & 1240 & \\
\hline 2078 & 2077 & \multirow{3}{*}{$\begin{array}{l}\text { structure of hydrogen } \\
\text { bonds and into process of } \\
\text { bond } \\
\text { formation and cleaveage }\end{array}$} & 1005 & 1120 & \multirow{3}{*}{$\begin{array}{l}\mathrm{C}-\mathrm{O} \text { stretch coupled with } \\
\text { in-plane bending of } \mathrm{C}-\mathrm{H} \\
\text { mode }\end{array}$} \\
\hline 2062 & 2062 & & 927 & 1078 & \\
\hline \multirow[t]{17}{*}{2030} & 2034 & & 901 & 1002 & \\
\hline & & O-D stretch & 820 & 894 & \multirow{7}{*}{$\begin{array}{l}\mathrm{C}-\mathrm{O}-\mathrm{H} \text { and }-\mathrm{C}=\mathrm{O} \text { group } \\
\text { bending }\end{array}$} \\
\hline & & & 718 & 829 & \\
\hline & & & 597 & 806 & \\
\hline & & & 549 & 710 & \\
\hline & & & 430 & 618 & \\
\hline & & & 323 & 642 & \\
\hline & & & 276 & 506 & \\
\hline & & & 172 & 438 & \multirow[t]{2}{*}{$\mathrm{C}=\mathrm{O}$ stretching band } \\
\hline & & & & 311 & \\
\hline & & & & 290 & \multirow{3}{*}{$\begin{array}{l}\text { OH tortional mode } \\
\text { out-of plane bending of } \\
\mathrm{C}-\mathrm{O}-\mathrm{H}\end{array}$} \\
\hline & & & & 260 & \\
\hline & & & & 198 & \\
\hline & & & & 168 & \multirow{4}{*}{$\begin{array}{l}\text { The bond correlated with } \\
\text { out-of-plane bending mode } \\
\text { of C-O-H } \\
\text { out-of-plane bending mode } \\
\text { of hydrogen bonding }\end{array}$} \\
\hline & & & & 142 & \\
\hline & & & & 123 & \\
\hline & & & & & \\
\hline
\end{tabular}

for doping the lead iodide crystals. The first reports of light effects on nucleation in solution date from 1900, and similar effects in gels have also been reported from time to time $[23,40]$. The chemistry, involved in the follwing processes:

$$
\mathrm{Pb}\left(\mathrm{C}_{2} \mathrm{H}_{3} \mathrm{O}_{2}\right)_{2}+2 \mathrm{KI} \longrightarrow \mathrm{PbI}_{2}+\mathrm{K}_{2}\left(\mathrm{C}_{2} \mathrm{H}_{3} \mathrm{O}_{2}\right)_{2} \text {. }
$$

The appearance of "zigzags" yellowish crystals as shown in Figure 1 could be viewed through the boiling test tube. In this note we report our own results of a Raman study of a single crystal of lead iodide, the assignment of Raman frequencies involving mainly motion of lead ions and modes involving mainly halogen ions [26]. Some surface barrier properties of lead iodide crystals are reported in physica status solidi(a). The barrier layer at a free surface of a $\mathrm{PbI}_{2}$ crystal surrounded by a non polar gas has been found to exhibit pronounced voltage rectification when passed by an alternating current of constant amplitude. The light induced relaxation of $v_{s}$ has a half-life time $\tau_{1 / 2}=\tau_{o}^{\exp u / k T}$, where $u$ is the activation energy [27]. Optical properties of lead iodide are reported in [28, 29] reports the third order nonlinear optical characteristics of new chalcohalogenide glass containing lead iodide.

2.2. Lead Tartrate Dihydrate Single Crystal Synthesis. In the present experiment, the possible reaction is $\mathrm{Pb}\left(\mathrm{NO}_{3}\right)_{2}+$ $\mathrm{C}_{4} \mathrm{H}_{6} \mathrm{O}_{6} \rightarrow \mathrm{PbC}_{4} \mathrm{H}_{6} \mathrm{O}_{6}+2 \mathrm{HNO}_{3}$.

In about an hour, a white color diffused from the top of the gel to the lower regions [26] of the gel of pH4.5. After 10 days, the precipitates extended to a depth of $6.3 \mathrm{~cm}$ from the gel surface as shown in Figure 2 were assigned on the basis of the characteristic vibrations of $\left(\mathrm{C}_{4} \mathrm{H}_{4} \mathrm{O}_{6}\right)^{2-}$ ion and $\mathrm{H}_{2} \mathrm{O}$. A free tartrate ion in zigzag planar configuration has $\mathrm{C} 2$ symmetry. The $\left(\mathrm{C}_{4} \mathrm{H}_{4} \mathrm{O}_{6}\right)^{2-}$ consists of two halves, 


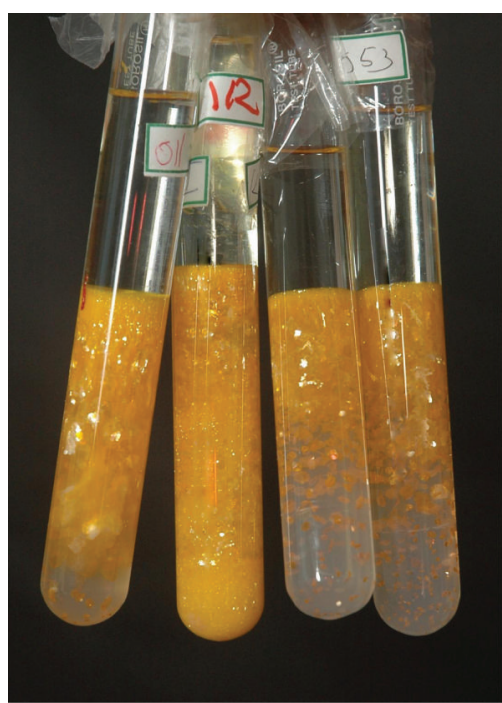

FIgURE 1: Synthesis of lead iodide single crystals.

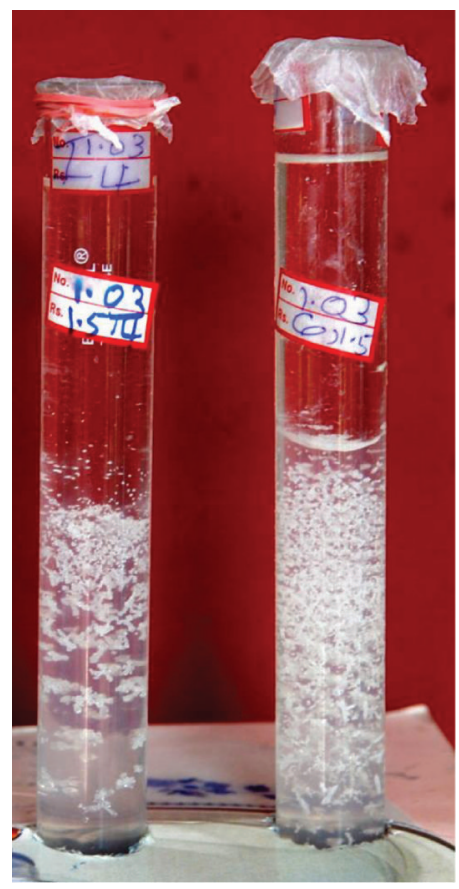

FIGURE 2: Synthesis of lead tartrate single crystals.

each half consisting of a carboxylic group tetrahedral carbon and hydroxyl oxygen, the halves are bridged through bonds. The multiplicity of Raman stretching bands suggests the presence of at least two crystallographically distinct water molecules in the hydrated compounds. The phenomenon of transformation of dendrites into single crystals of lead tartrate indicates that it may be useful in the growth of single crystals of materials which normally grow as dendrites. It is now well established that surface energy and surface diffusion are decisive factors on the shape stability of spherical particles [30]. But the reduction in size is remarkable in the case of cadmium doped crystals. The dendritic growth of lead tartrate in gel media is already reported by [27].

\section{Result}

It has been shown that equilibrium charges and charge flux from electromagnetic radiations account quantitatively for several intermolecular electronic effects including induction and hyperconjugation $[31,32]$. The interaction occurs with the releasing of electronic charge from $\sigma_{\mathrm{C}-\mathrm{H}}$ to the $\mathrm{C}-\mathrm{C}$ bond. In lead tartrate dehydrate, the most evident effect of this interaction is that the $\mathrm{C}-\mathrm{C}$ bond decreases in length from its normal value and increases in strength [33-36], but effect of hyperconjugation can also be on $\mathrm{C}-\mathrm{H}$ bonds. Electromagnetic radiation intensities have been directly correlated to spectral patterns. The asymmetric $\mathrm{C}-\mathrm{H}$ stretching mode of tartrate ion is expected in the region around $2943 \mathrm{~cm}^{-1}$. The $\mathrm{O}-\mathrm{H}-\mathrm{O}$, intermolecular $\mathrm{O}-\mathrm{H}$ bonding of the hydroxyl group with carbonyl group, causes the lowering of the $\mathrm{O}-\mathrm{H}$ stretching mode. The calculated results help revealing for the first time that the synthesized molecule has microscopic nonlinear optical behavior with nonzero hyperpolarizability values. The electron donor group $-\mathrm{OH}$ and $-\mathrm{CH}$ and acceptor group $-\mathrm{C}=\mathrm{O}$ play important role in the magnitude of second order polarizability. In lead iodide dihydrate sample, the analysis shows that the limited number of vibration peaks indicates the absence of second order harmonic generations while the hydroxyl stretching and bending bands can be identified by their broadness and strength of the band which depends on the extend of hydrogen bond [3740]. Hydroxyl stretching vibrations are generally observed in the region around $3500 \mathrm{~cm}^{-1}$. The hydroxyl stretching bands split into different bands that correspond to $\mathrm{O}-\mathrm{H}$ and $\mathrm{O}-$ D. Interaction of lone pairs of oxygen (electron donor) with the $\mathrm{O}-\mathrm{H}$ antibonding orbital leads to an increase of electron populations in this orbital, followed by a weakening of the $\mathrm{O}-\mathrm{H}$ bond, which is accompanied by a lowering of the $\mathrm{O}-$ $\mathrm{H}$ stretching wavenumber. This explains the formation of the strong intermolecular hydrogen bonding between $\mathrm{O}-\mathrm{H}$ group and lone pair of $\mathrm{O}$ in the molecule. Hydrogen bonding interaction leads to an increase in electron density of lead iodide crystals $[41,42]$. It is evident that the electron density in $\mathrm{O}-\mathrm{H}$ antibonding orbitals was significantly increased by the strong hydrogen bond between hydroxyl group (O$\mathrm{H}$ ) and lone pair of oxygen in the molecule providing unambiguous evidence about the weakening of the bond, its elongation, and shifts of the hydroxyl stretching frequency. Low wave number vibrations of hydrogen bonds indicate the attractive interaction between the hydrogen donor group and the acceptor metal group [43]. The low wave number degrees of freedom such as liberation as well as interaction induced give rise to additional absorption and Raman bands that frequently overlap with the bands of the hydrogen bond modes. The band in Raman at $96 \mathrm{~cm}^{-1}$ has been attributed to the translational motion of the hydrogenbonded molecules including some bending component. The lattice vibrations of rotating type are generally stronger in intensity than the translatory type [27]. The lattice modes 

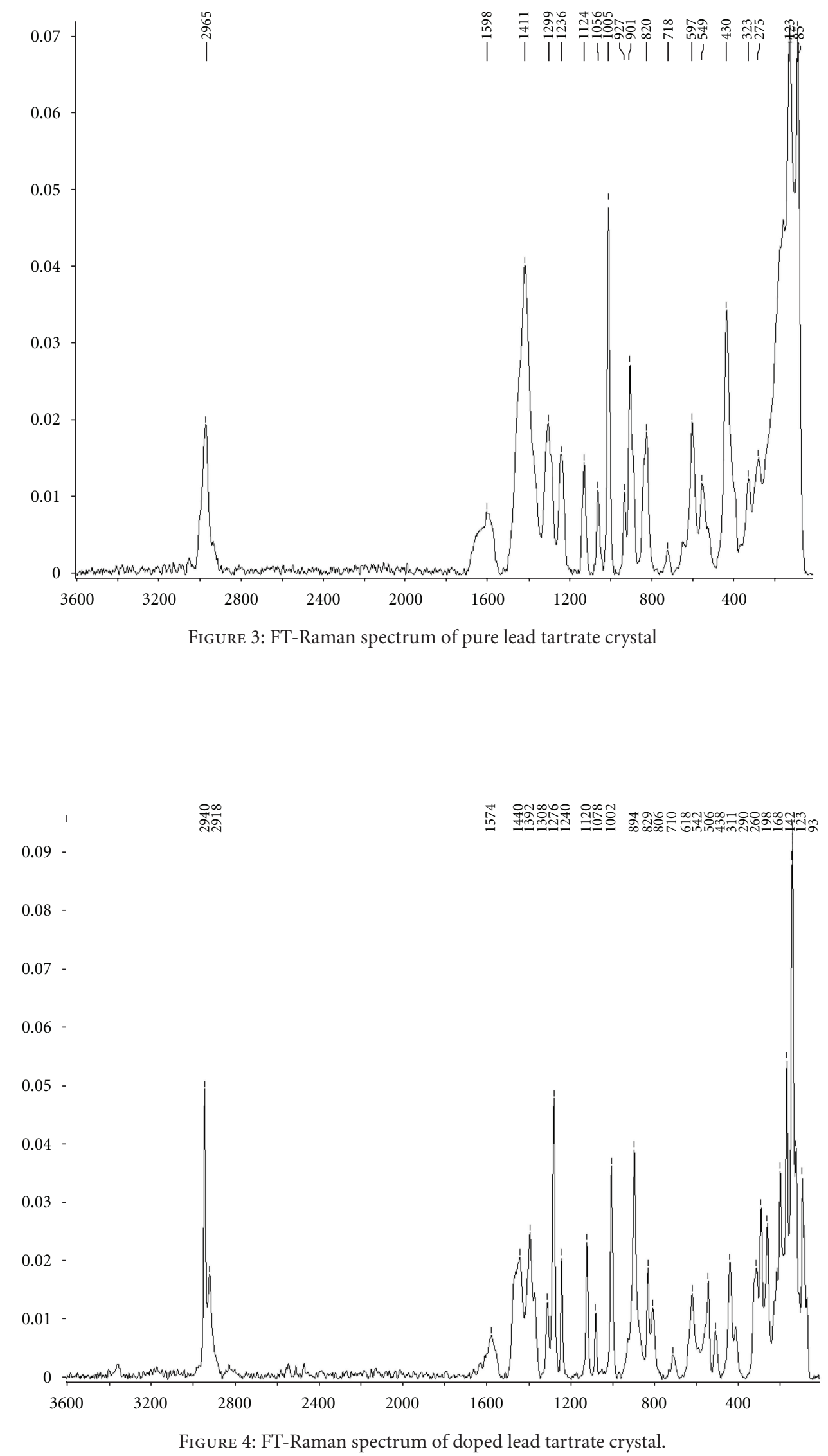


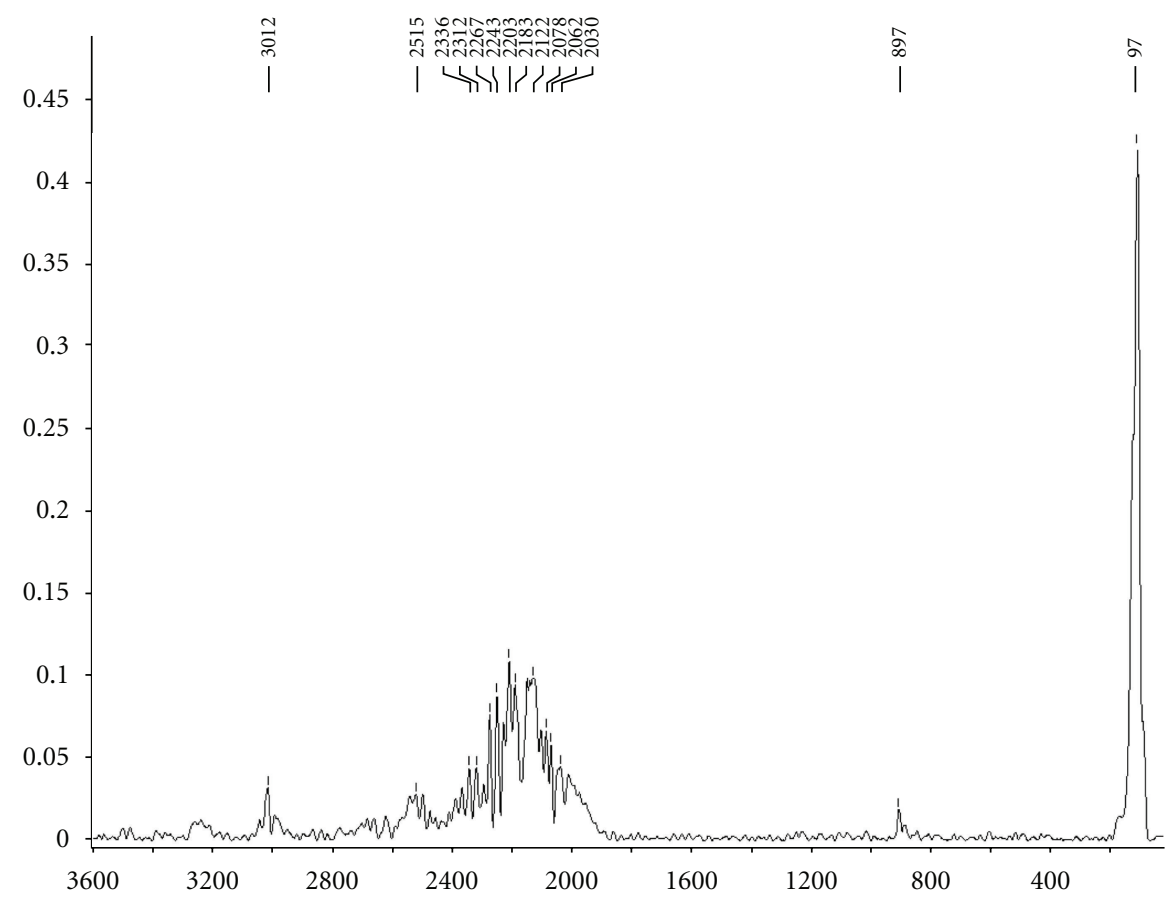

Figure 5: Fourier Transform Raman Spectrum of Pure Lead iodide crystal.

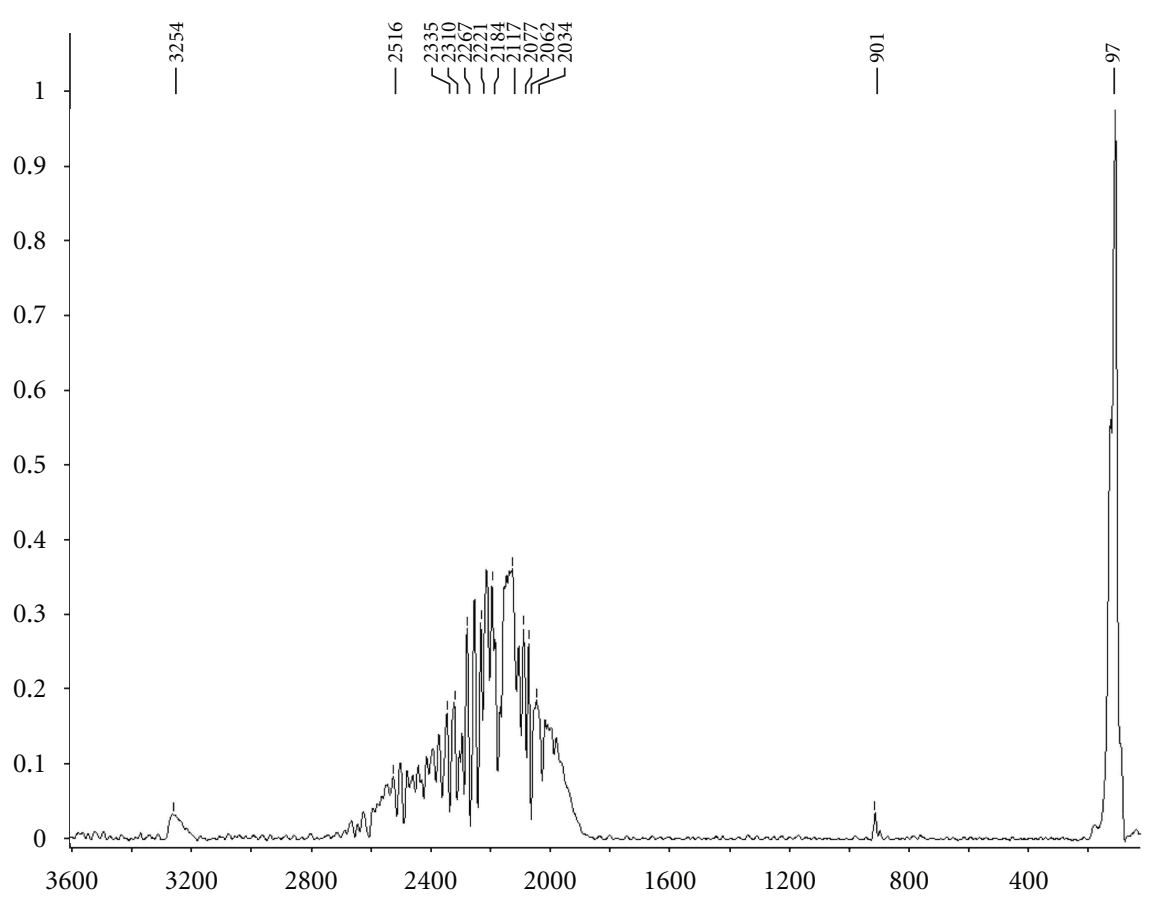

Figure 6: Fourier Transform Raman Spectrum of doped Lead iodide crystal.

are very intense in Raman. The calculations results also reveal that the synthesized molecule might have NLO behavior with nonzero polarization values. $\left(\mathrm{C}_{4} \mathrm{H}_{4} \mathrm{O}_{6}\right)^{2-}$ is a tartrate ion [36-39], whereas in $\mathrm{PbI}_{2} \cdot 2 \mathrm{H}_{2} \mathrm{O}$, I-Pb-I-Pb-I is the structure of lead iodide crystals forming a vandervals bond between iodine atom. The analysis of bands obtained in Raman spectrum of lead tartrate and lead iodide crystals grown in pure and doped is shown in Table 1. In the stretching region, the tartrate ions and iodide give only limited resonating peaks, whereas in the region of nonlinearity the lead tartrate 
gives large number of sharp peaks of the carbonyl, C$\mathrm{H}, \mathrm{O}-\mathrm{H}$ all are in a state of tension and producing the peaks due to rocking torsion, in-plane,and out-of-plane bending of the functional group and the $\mathrm{H}-\mathrm{O}-\mathrm{H}$ group associated with the crystal. The bands at $500-548 \mathrm{~cm}^{-1}$ in the Raman spectrum have been identified as the $\mathrm{O}-$ $\mathrm{H}$ torsion mode. Hence, the band position of the $\mathrm{O}-\mathrm{H}$ torsional mode may serve as a sensitive measure of the strength of the interaction between the $\mathrm{O}-\mathrm{H}$ group and the lone pair electron of neighboring oxygen atom. The attractive interaction between the hydrogen donor group and the acceptor metal group leads to the occurrence of new vibrational degrees of freedom, the so-called hydrogen bond modes are connected with elongations, the relative distance between the metal and the associate ions and the relative orientations of the hydrogen bonded groups. Weak attractive interaction along the hydrogen bond, hydrogen bond mode occurs at low wave numbers in the range between 50 and $300 \mathrm{~cm}^{-1}$. The bands at $57.44 \mathrm{~cm}^{-1}$ of lead tartrate have been attributed to the translational motion of the hydrogenbonded molecules including some bending component. The lattice vibrations of rotatory type are generally stronger in intensity than the translator type. In lead iodide spectrum, the metal deformation bands occur at $96.88 \mathrm{~cm}^{-1}$ cause the lowering of the $\mathrm{O}-\mathrm{H}$ stretching mode. In hydrogen-bonded inorganic systems, combination of bending modes with the internal rotation mode indicates that the ion is not rotating freely in the crystalline lattice. Crystal materials are widely used in many electro-optics fields, growing technologies and preparing technologies for nonlinear optical crystals. The high stability of $\mathrm{PbI}_{2}$ verified by Raman spectra analysis. The results allow us to understand, at least partially, lead iodide crystal can yield noncentrosymmetrical by optical methods. Multiple bands present in the stretching region of water in the Raman spectrum with weak intensity in the region $2515-2003 \mathrm{~cm}^{-1}$ indicate the presence of hydrogen bonds of various strengths. On deuteration, the stretching modes of water molecules are shifted towards the low wave number region. Hydrogen bonding is an important interaction determining the structure and functionality of numerous molecular systems in nature Fermi resonance with the overtones of the $\delta(\mathrm{OH})$ and $v(\mathrm{OH})$ modes split into different bands near $2115-200 \mathrm{~cm}^{-1}$. Stretching modes appear below $300 \mathrm{~cm}^{-1} \mathrm{C}=\mathrm{O}-\mathrm{H}$, the splitting of the carbonyl mode may be attributed to intermolecular association based on $\mathrm{C}=\mathrm{O} \cdots \mathrm{H}$ type hydrogen bonding in the molecule and the structural and functional asymmetry in the carbonyl groups as shown in Figures 3 and 4. When a carbonyl group is participating in hydrogen bond and resonance can occur which puts a partial negative charge on the oxygen atom accepting the hydrogen bond and positive charge on the atom donating the hydrogen, the partial transfer of allegiances of the proton enhances resonance and lowers the $\mathrm{CO}$ stretching wave numbers. These mechanisms may be playing an important role in the biological activity. Raman spectrum can be used not only to obtain standard information, but also to evaluate the vibrational contribution (polarizability) to molecular hyperpolarization.

\section{Conclusion}

For tartrate group it is significant to consider a harmonic coupling for the low wave number modes, Fermi resonances with finger print vibrations ( $\mathrm{O}-\mathrm{H}$ bending and $\mathrm{C}=\mathrm{O}$ stretch), and excitonic coupling between $\mathrm{OH}$ stretching modes, also known as Davydov coupling [43]. It is considered that stretching vibrations of the proton in the hydrogen bonded $\mathrm{O}-\mathrm{H}-\mathrm{O}$ are harmonically coupled to the hydrogen bond stretching vibrations. The splitting and lowering of the carbonyl stretching vibrational modes of tartrate indicate intermolecular association based on $\mathrm{C}=\mathrm{O}-\mathrm{H}$ type hydrogen bonding in the molecule. Raman spectrum corresponds to wave number $97 \mathrm{~cm}^{-1}$ is assigned to metal legands as shown in Figures 5 and 6. And wave number $1286 \mathrm{~cm}^{-1}$ is assigned to $\mathrm{C}-\mathrm{O}$ stretching mode coupled with $\mathrm{C}-\mathrm{H}$ in-plane bending mode of lead tartrate. Metal organic group of crystals thus belongs to second-order nonlinearity and metal inorganic group crystals correspond to third-order nonlinear crystals. Our results compared the motion of lead ions and the motion of functional groups in both the compounds using Raman spectra.

\section{Acknowledgments}

The authors are much indebted to Dr. Sreekumar, scientists of the technical Institute Sree Chithra, Trivandrum for providing Raman Spectra of lead iodide and lead tartrate. they are grateful to the Head of the Research department M.G and his College Trivandrum, Kerala for providing facilities. The authors are also thankful to Dr. RajendraBabu, Reader, M.G and his College Trivandrum for valuable help in the entire work. One of the authors (G.Lillybai) also thanks UGC for awarding a teacher fellowship.

\section{References}

[1] K. S. Shah, F. Olschner, L. P. Moy et al., "Lead iodide Xray detection systems," Nuclear Instruments and Methods in Physics Research, Section A, vol. 380, no. 1-2, pp. 266-270, 1996.

[2] T. Shoji, K. Ohba, T. Suehiro, and Y. Hiratate, "Characterization of $\mathrm{PbI}_{2}$ radiation detectors using the response of $\alpha$-rays," IEEE Transactions on Nuclear Science, vol. 41, no. 4, part 1, pp. 694-697, 1994.

[3] T. Shoji, K. Ohba, T. Suehiro, and Y. Hiratate, "Fabrication of radiation detector using $\mathrm{PbI}_{2}$ crystal," IEEE Transactions on Nuclear Science, vol. 42, no. 4, part 1, pp. 659-662, 1995.

[4] A. Burger, S. H. Morgan, E. Silberman, D. Nason, and A. Y. Cheng, "A review of recent measurements of optical and thermal properties of $\alpha$-mercuric iodide," Nuclear Instruments and Methods in Physics Research Section A, vol. 322, no. 3, pp. 427-431, 1992.

[5] A. Ferreira da Silva, N. Veissid, C. Y. An, I. Pepe, N. Barros de Oliveira, and A. V. Batista da Silva, "Optical determination of the direct bandgap energy of lead iodide crystals," Applied Physics Letters, vol. 69, no. 13, pp. 1930-1932, 1996.

[6] T. S. Silva, A. S. Alves, I. Pepe et al., "Thermal diffusivity of lead iodide," Journal of Applied Physics, vol. 83, no. 11, pp. 61936195, 1998. 
[7] D. S. Bhavsar and K. B. Saraf, "Morphology of $\mathrm{PbI}_{2}$ crystals grown by gel method," Crystal Research and Technology, vol. 37, no. 1, pp. 51-55, 2002.

[8] K. P. O'Donnell and X. Chen, "Temperature dependence of semiconductor band gaps," Applied Physics Letters, vol. 58, no. 25, pp. 2924-2926, 1991.

[9] R. Ahuja, H. Arwin, A. Ferreira da Silva et al., "Electronic and optical properties of lead iodide," Journal of Applied Physics, vol. 92, no. 12, pp. 7219-7224, 2002.

[10] Y. P. Varshini, "Temperature dependence of the energy gap in semiconductors," Physica, vol. 34, p. 149, 1967.

[11] R. Ahuja, A. Ferreira da Silva, C. Persson et al., "Optical properties of 4H-SiC," Journal of Applied Physics, vol. 91, no. 3, pp. 2099-2103, 2002.

[12] J. M. Wills and B. R. Cooper, "Synthesis of band and model Hamiltonian theory for hybridizing cerium systems," Physical Review B, vol. 36, no. 7, pp. 3809-3823, 1987.

[13] D. L. Price and B. R. Cooper, "Total energies and bonding for crystallographic structures in titanium-carbon and tungstencarbon systems," Physical Review B, vol. 39, no. 8, pp. 49454957, 1989.

[14] L. Hedin and B. I. Lundqvist, "Explicit local exchangecorrelation potentials," Journal of Physics C, vol. 4, no. 14, pp. 2064-2083, 1971.

[15] O. K. Andersen, "Linear methods in band theory," Physical Review B, vol. 12, no. 8, pp. 3060-3083, 1975.

[16] H. L. Skriver, The LMTO Method, Springer, Berlin, Germany, 1984.

[17] D. J. Chadi and M. L. Cohen, "Special points in the brillouin zone," Physical Review B, vol. 8, no. 12, pp. 5747-5753, 1973.

[18] S. Froyen, "Brillouin-zone integration by Fourier quadrature: special points for superlattice and supercell calculations," Physical Review B, vol. 39, no. 5, pp. 3168-3172, 1989.

[19] T. Gashe, A Good Description of the Calculation of Dielectric Constant and Related Properties Are Found in the Thesis, Uppsala University, 1993.

[20] A. R. Edmonds, Angular Momentum in Quantum Mechanics, Princeton University Press, Princeton, NJ, USA, 1974.

[21] K. S. Shah, P. Bennett, M. Klugerman et al., "Lead iodide optical detectors for gamma ray spectroscopy," IEEE Transactions on Nuclear Science, vol. 44, no. 3, part 1, pp. 448-450, 1997.

[22] R. Ahuja, S. Auluck, J. M. Wills, M. Alouani, B. Johansson, and O. Eriksson, "Optical properties of graphite from firstprinciples calculations," Physical Review B, vol. 55, no. 8, pp. 4999-5005, 1997.

[23] J. Dennis and H. K. Henisch, "Nucleation and growth of crystals in gels," Journal of the Electrochemical Society, vol. 114, no. 3, pp. 263-266, 1967.

[24] H. K. Henisch and C. Srinivasagopalan, "Properties of semiconducting lead iodide," Solid State Communications, vol. 4, no. 9, pp. 415-418, 1966.

[25] A. R. Patel and H. L. Bhat, "Growth of single crystals of $\mathrm{BaSO}_{4}$ and $\mathrm{SrSO}_{4}$ from gels," Journal of Crystal Growth, vol. 12, no. 4, pp. 288-290, 1972.

[26] A. V. Sienkiewicz and V. N. Kokozay, "Crystal structure of chloride and iodide complexes of lead(II) with 2dimethylaminoethanol obtained by direct synthesis," Polyhedron, vol. 13, no. 9, pp. 1439-1444, 1994.

[27] M. Abdulkhadar and M. A. Ittyachen, "New gel method for growing large needles and single crystals of lead chloride," Journal of Crystal Growth, vol. 48, no. 1, pp. 149-154, 1980.

[28] Y. L. Yousef, S. Aziz, and A. Mishriky, "Some surface barrier properties of lead iodide crystals," Physica Status Solidi A, vol. 1, no. 1, pp. 153-158, 1970.
[29] D. S. Bhavsar and K. B. Saraf, "Optical properties of lead iodide between 0.4946 and 6.185 eV," Journal of Materials Science: Materials in Electronics, vol. 14, no. 4, pp. 195-198, 2003.

[30] Y. Makita and Y. Takagi, "Ferroelectric and optical properties of $\mathrm{Na}(\mathrm{K}-\mathrm{NH} 4)$-tartrate mixed crystals," Journal of the Physical Society of Japan, vol. 13, no. 4, pp. 367-377, 1958.

[31] A. Sawada and Y. Takagi, "Mechanism of ferroelectric phase transition in ammonium Rochelle salt," Journal of the Physical Society of Japan, vol. 33, no. 4, pp. 1071-1075, 1972.

[32] Y. Ishibashi and Y. Takagi, "New interpretation of phase transition in ammonium Rochelle salt by order-disorder mechanism," Journal of the Physical Society of Japan, vol. 38, no. 6, pp. 1715-1719, 1975.

[33] K. Verrhet, L. Dupre, and Boulange-Permann, American Journal of Enology and Viticulture, pp. 9391-9397, 1999.

[34] L. Tatush, L. M. Rabkin, V. I. Torgashev, Y.-I. Yuzyuk, L. A. Shuvalov, and N. M. Schagina, Ferroelectrics, vol. 75, p. 455, 1987.

[35] I. Kanesaka and H. Kita, "Vibrational study on ferroelectric dipoles in rochelle salt," Journal of Raman Spectroscopy, vol. 22, pp. 657-661, 1991.

[36] Y. Iwata, S. Mitani, and I. Shibuya, Freeoelectrics, vol. 96, p. 215, 1988.

[37] I. Kanesaka and H. Kita, "Vibrational study on phase transition in ammonium Rochelle salt," Journal of Raman Spectroscopy, vol. 23, no. 11, pp. 585-588, 1992.

[38] H. K. Henisch, Crystal Growth in Gels, The Pennsylvania State University Press, University Park, London, UK, 1970.

[39] J. I. Hanoka, "Gel cusps and crystal growth in gels," Journal of Applied Physics, vol. 40, no. 7, pp. 2694-2696, 1969.

[40] H. K. Hektisch, J. Dennis, and J. I. Hanoka, "Crystal growth in gels," Journal of Physics and Chemistry of Solids, vol. 26, no. 3, pp. 493-496, 1965.

[41] P. W. Lau and W. C. Lin, "Electron spin resonance of transition metal ions in calcium tartrate tetrahydrate. II. $\mathrm{VO}^{2+}$ as dopant," The Journal of Chemical Physics, pp. 3988-3991, 1970.

[42] G. Sperka, Ph.D. thesis, Graz University of Technology, 1987.

[43] P. H. Egli and L. R. Johnson, "Ionic salts," in The Art and Science of Growing Crystals, pp. 194-213, John Wiley \& Sons, New York, NY, USA, 1963. 

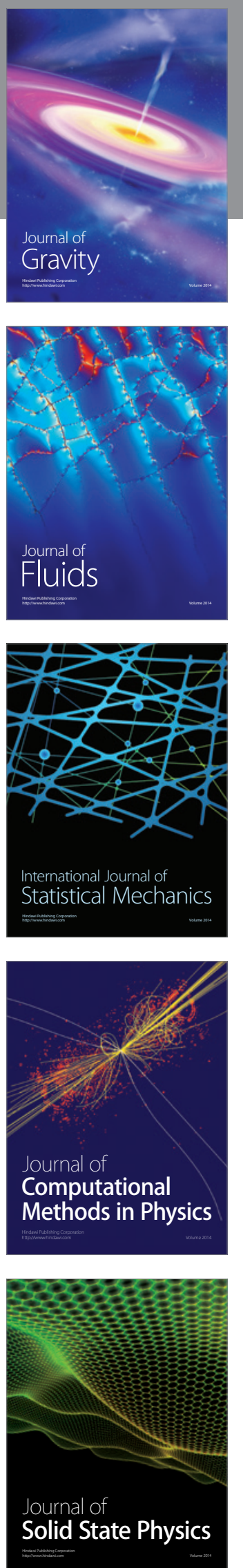

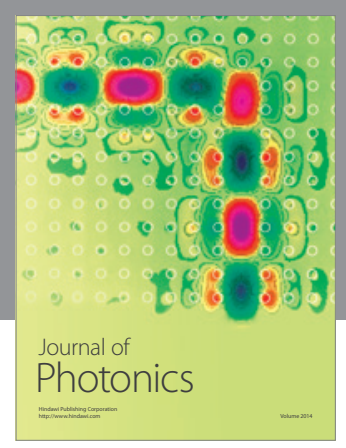

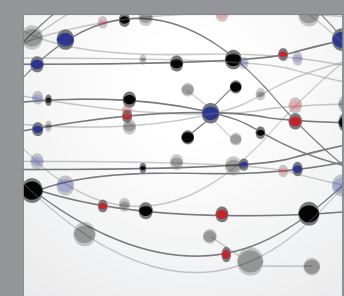

The Scientific World Journal
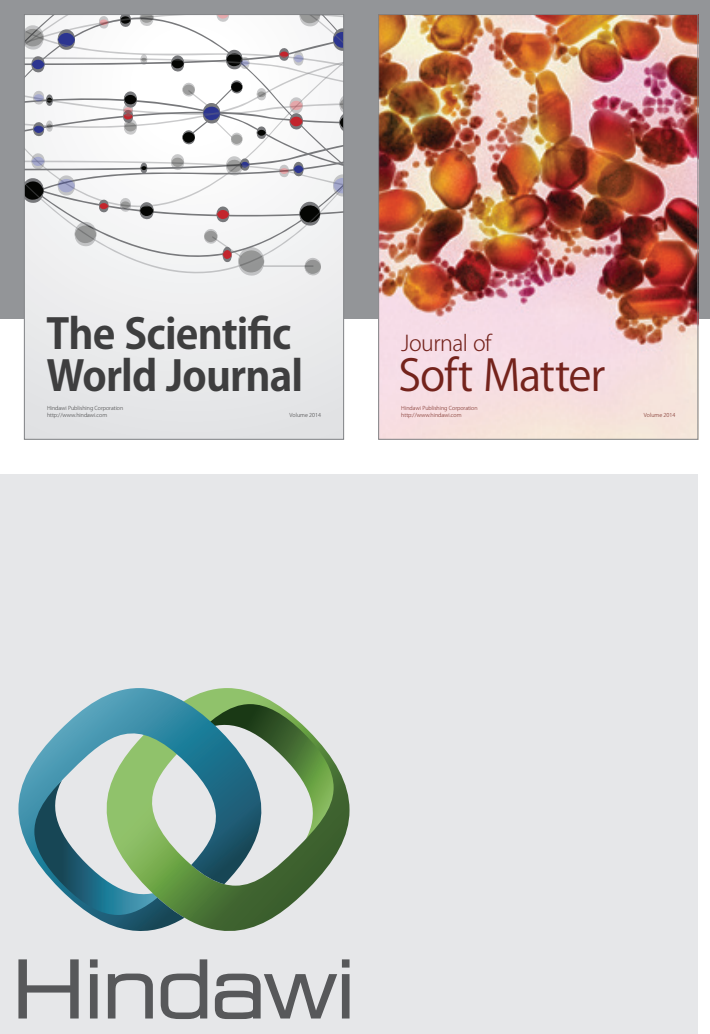

Submit your manuscripts at

http://www.hindawi.com
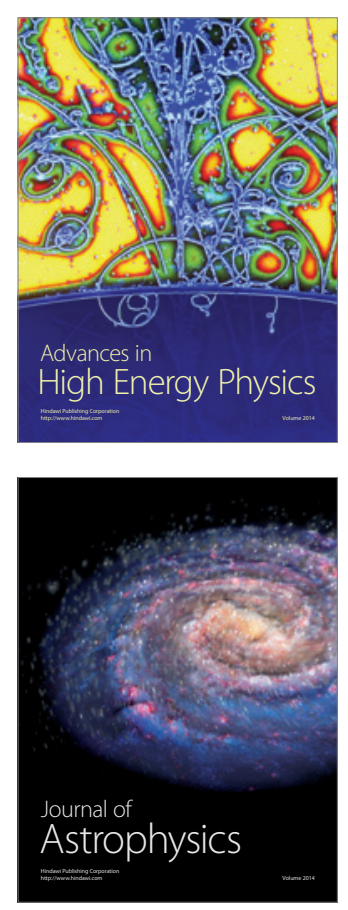
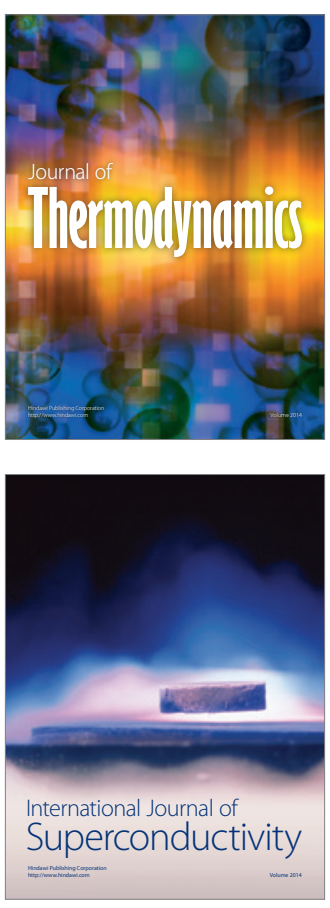
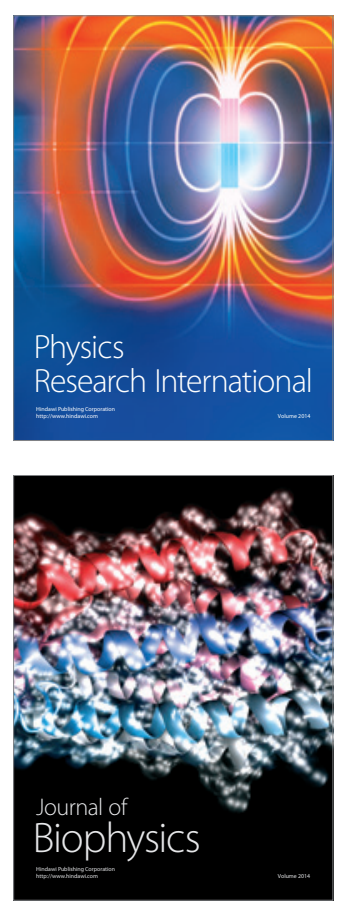
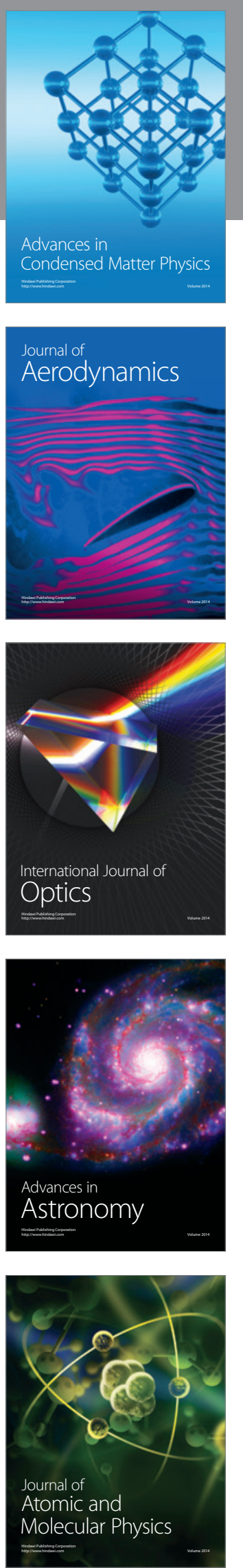